\title{
SCREENING OF THYROID DISORDER AMONG PREGNANT LADIES IN A TERTIARY HOSPITAL OF NEPAL
}

\author{
Shrestha $B^{1}$, Adhikari $P^{2}$
}

${ }^{1}$ Department of Obstetrics and Gynaecology, ${ }^{2}$ Department of General Medicine, Nepal Medical College Teaching Hospital, Attarkhel, Gokarneshwor-8, Kathmandu, Nepal

\begin{abstract}
Thyroid disorders (TD) are the second most common endocrine disorders seen in pregnancy. Many physiological changes in pregnancy lead to hypothyroidism in pregnancy. Hypothyroid in pregnancy is associated with many adverse maternal and fetal outcomes. Objective of this study was to find the prevalence of TD in pregnancy in Nepal Medical College Teaching Hospital (NMCTH), Antithyroid Peroxidase Antibody (TPO-Ab) positive cases with hypothyroidism and to evaluate maternal fetal outcome in hypothyroid pregnancies. This was a prospective hospital based observational study. The study was done in Department of Obstetrics and Gynecology, NMCTH from August 2018 to July 2019. Among 420 pregnant ladies $71.0 \%$ were euthyroid, $25.7 \%$ were hypothyroid $(25.2 \%$ of subclinical and $0.5 \%$ overt), $3.3 \%$ were hyperthyroid $(0.7 \%$ of overt) and $6.4 \%$ were $\mathrm{TPO}-\mathrm{Ab}$ positive with hypothyroidism. Inspite of treatment, Gestational hypertention, Pre-eclampsea and LSCS is significantly high in hypothyroid pregnancy than euthyroid pregnancy. High prevalence of hypothyroidism in this study necessitates universal screening of TD at first trimester of pregnancy.
\end{abstract}

\section{KEYWORDS}

Thyroid disorder, hypothyroid, euthyroid, subclinical, overt

\section{CORRESPONDING AUTHOR}

Dr. Biloni Shrestha (Vaidya), Assistant Professor,

Department of Obstetrics/Gynecology,

Nepal Medical College and Teaching Hospital, Attarkhel, Gorkerneshwor-8, Kathmandu, Nepal.

E-mail: drbiloni@hotmail.com

ORCID ID: 0000-0001-5747-3683 


\section{INTRODUCTION}

Thyroid disorders (TD) are the second most common endocrine disorders seen in pregnancy. TD is known to be associated with adverse maternal and fetal outcomes and is often overlooked in pregnant women because of nonspecific symptoms and hyper-metabolic state of pregnancy. ${ }^{1}$

Pregnancy is associated with many physiological changes which lead to hypothyroidism. Pregnancy is a state of relative iodine deficiency because of increase renal loss and transfer of iodine to developing fetus. High estrogen level in pregnancy causes increased level of thyroxine-binding globulin (TBG). Serum thyrotropin level in early pregnancy decreases because of thyroid stimulation from the weak thyroid stimulating hormone (TSH), effects of human chorionic gonadotrophin (HCG). It leads to increased FT4 and decreased TSH. ${ }^{2}$

Throughout the pregnancy maternal thyroxin is transferred to fetus. ${ }^{3}$ Maternal thyroxin is important for normal fetal brain development, especially prior to development of fetal thyroid gland. ${ }^{4}$ Overt hypothyroidism $(\mathrm{OH})$, characterized by an elevated serum TSH and subnormal FT4. Subclinical hypothyroidism ( $\mathrm{SCH})$, is characterized by an elevated serum TSH with normal free thyroxine (FT4). Hypothyroid in pregnancy is observed not equally in different studies..$^{5-9}$ The prevalence of $\mathrm{OH}$ in pregnancy was 2 per 1000 births. ${ }^{9} \mathrm{OH}$ is defined as a serum TSH level below the trimester-specific reference range with elevated levels of free T3, free T4 or both. SCH is defined as a serum TSH level below the trimester-specific reference range with normal levels of free T3 and T4.

Overt and subclinical maternal hypothyroidism in pregnancy has been associated with adverse maternal and fetal outcomes in observational studies including miscarriages, anaemia, eclampsia, pre-eclampsia, placental abnormalities, preterm labor, low birth weights, Intra uterine growth retardation (IUGR) and still birth. ${ }^{10-14}$ Haddow et $a l$, in 1999 first described reduced intelligence quotient (IQ) in babies born from hypothyroid mothers corroborating the association between hypothyroidism and increase risk of impaired neurodevelopment in the offspring. ${ }^{15}$

There are few researches done in TD among pregnant ladies in our country. The objective of this study was to find out the prevalence of TD in pregnancy in NMCTH. It will also help to find out the prevalence of hypothyroidism (overt and subclinical) and the Antithyroid Peroxidase Antibody (TPO-Ab) positive cases among hypothyroid females.

\section{MATERIALS AND METHODS}

This was a prospective hospital based observational study. The study was done in the Department of
Obstetrics and Gynecology, NMCTH, a tertiary care hospital situated in Kathmandu. This study was done over a period of one year (August 2018 to July 2019).

After approval of proposal by NMCTH Institutional Review Committee, all women who had singleton pregnancy irrespective of age, parity and socioeconomic status were included in the study. Those with multiple gestation, who had been previously diagnosed to have thyroid abnormality and the pregnant women who were already on treatment for TD were excluded. All the pregnant ladies in their $1^{\text {st }}$ trimester and coming to Obstetrics and Gynecology were enrolled in the study. Verbal and written consent was taken from all the patients and the blood sample was sent for thyroid function test (TFT). Report was collected and was evaluated according to trimester specific reference ranges ${ }^{16}$ which suggest that the upper limit of TSH should be $2.5 \mathrm{mIU} / \mathrm{L}$ in the $1^{\text {st }}$ trimester, and $3.0 \mathrm{mIU} / \mathrm{L}$ in the $2^{\text {nd }}$ and $3^{\text {rd }}$ trimesters.

In case of hypothyroidism, TPO-Ab test was done. TSH was again repeated on $2^{\text {nd }}$ and $3^{\text {rd }}$ trimester in euthyroid pregnant females. All the cases of hypothyrodism were treated. Pregnant ladies with TSH more than $4 \mathrm{mIU} / \mathrm{l}$ were treated with lthyroxin dose was adjusted. If TSH was $2.5 \mathrm{mIU} / \mathrm{l}$ in $1^{\text {st }}$ trimester and $3 \mathrm{mIU} / \mathrm{l}$ in $2^{\text {nd }}$ and $3^{\text {rd }}$ trimester with positive anti TPO-Ab, minimum dose of 1 thyroxin was given and TSH was monitered every month and drug was adjusted accordingly.

Among 420 enrolled cases, 268 cases were followed up till discharge after delivery. All the data were entered and analysed by SPSS version 16 . Fisher's exact test was used for data analysis. Statistical significance was considered as $\mathrm{P}$ value $\leq 0.05$.

\section{RESULTS}

Among 420 cases, $71.0 \%$ were euthyroid, $25.7 \%$ were hypothyroid and 3.3\% were hyperthyroid. Among 108 hypothyroid cases, $25.2 \%$ were SCH and $0.5 \%$ were $\mathrm{OH}$. Among $3.3 \%$ hyperthyroid cases $0.7 \%$ were $\mathrm{OH}$ and rest were SCH. Hypothyroidism was seen in $14.5 \%$ primigravida and $11.2 \%$ multigravida. Hyperthyroidism was seen $1.4 \%$ in primigravida and $1.9 \%$ in multigravida. Out of total number of cases, $6.4 \%$ were TPO-Ab positive (Table 1).

One hundred and six cases (98.1\%) of hypothyroidism were diagnosed at first trimester and treated accordingly. Only two more cases of subclinical hypothyroidism were added in second trimester. In third trimester there were no new cases of hypothyroidism (Table 2).

All pregnant ladies with hypothyroidism and hyperthyroidism were treated after diagnosis. Complications are relatively high 
in hypothyroidism as compared to euthyroid patients, but statistically it was not significant. It was seen that gestational hypertention and Pre-eclampsea in hypothyroid pregnancy was significantly higher than euthyroid pregnancy.
(9.1\% versus $3.0 \%$, where $\mathrm{p}$ value is equal to 0.05$)$ (Table 3).

LSCS is significantly higher in hypothyroids than euthyroids ( $48.5 \%$ versus $18.8 \%$, $\mathrm{p}$ value equal to

\begin{tabular}{|lcccccccc|}
\multicolumn{7}{c}{ Table 1: TD in different trimesters, (Total n=420) } \\
Gravida & 420 & $298(71.0 \%)$ & Overt & Subclinical & Total & Overt & Subclinical & Total \\
Primi & 203 & $136(32.4 \%)$ & 1 & 60 & $61(14.5 \%)$ & 1 & 5 & $6(1.4 \%)$ \\
Multi & 217 & $162(38.6 \%)$ & 1 & 46 & $47(11.2 \%)$ & 2 & 6 & $8(1.9 \%)$ \\
Total & 420 & $298(71.0 \%)$ & $2(0.5 \%)$ & $106(25.2 \%)$ & $108(25.7 \%)$ & $3(0.7 \%)$ & $11(2.6 \%)$ & $14(3.3 \%)$ \\
\hline
\end{tabular}

\begin{tabular}{|lcccc|}
\hline \multicolumn{5}{|c|}{ Table 2: Hypothyroidism in different } \\
trimesters. (Total $\mathbf{n = 2 0}$ )
\end{tabular}

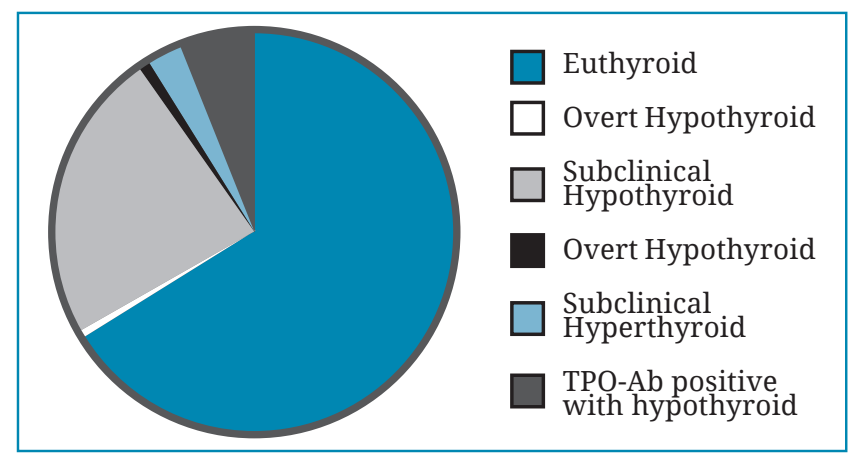

Fig. 1: Prevalence of Thyroid disorder in pregnancy
0.0005) (table 3). In $65 \%$ of cases indication for LSCS was fetal distress.

\section{DISCUSSION}

TD are second most common endocrine disorders in pregnancy and are associated with adverse maternal and fetal outcome in pregnancy. However, an early detection of thyroid dysfunction and treatment of mother during pregnancy improves the outcome. ${ }^{17}$ Early detection of TD during pregnancy is possible if the patient is suggested to do thyroid function test during her first prenatal visit or soon after the pregnancy is confirmed.

The prevalence of $25.7 \%$ hypothyroidism was found to be very high in our study. It indicates the necessity of universal screening of thyroid dysfunction in our place. There were $25.2 \%$ cases of subclinical hypothyroidism and $0.5 \%$ cases of overt hypothyroidism. Higher prevalence was found in the study done in western part of Nepal which showed $13.0 \%$ of $\mathrm{OH}$ and $31.0 \%$ of

Table 3: Complications among euthyroid and hypothyroid pregnancy

\section{Complications}

Spontaneous abortion

Gestational Hyperten-

sion, pre-eclampsia

Oligohydroamnios, IUGR

Severe anemia

Abruptio

Preterm delivery

LSCS

NICU admission

$\mathrm{PPH}$

\section{Euthyroid pregnancy 202}

$$
\begin{gathered}
1(0.5 \%) \\
6(3.0 \%) \\
2(1.0 \%) \\
1(0.5 \%) \\
0 \\
4(2.0 \%) \\
38(18.8 \%) \\
3(1.5 \%) \\
1(0.5 \%)
\end{gathered}
$$

Hypothyroid pregnancy 66

P value

$$
\begin{gathered}
1(1.5 \%) \\
6(9.1 \%) \\
3(4.5 \%) \\
1(1.5 \%) \\
1(1.5 \%) \\
3(4.6 \%) \\
32(48.5 \%) \\
4(6.1 \%) \\
1(1.5 \%)
\end{gathered}
$$

0.4976

0.0516

0.0996

0.4976

0.2805

0.2557

0.0005

0.0655

0.4976 
SCH. ${ }^{18}$ Prevalence is little low in the study done by Chaudhary et al, at eastern part of Nepal. SCH and $\mathrm{OH}$ were $19.5 \%$ and $1.1 \%$ respectively. ${ }^{19}$ In comparison to other studies done in different part of world prevalence of hypothyroidism is very high in Nepal. Nutritional factor may be one of the causes for this as there is high prevalance of iodine deficiency hypothyroidism in Nepal. ${ }^{20,21}$

Sing et al showed prevalence of hypothyroidism $7.5 \%(\mathrm{n}=30)$, of which $6.0 \%$ were $\mathrm{SCH}$ and $1.5 \%$ were $\mathrm{OH} .{ }^{22}$ In a study done by Sahu et al, prevalence of subclinical and overt hypothyroidism in India were $6.5 \%$ and $4.6 \%$, respectively. ${ }^{23}$ In a study done by Jayanthy et al, the prevalence of thyroid dysfunction was $12.0 \% .^{24}$ Similar finding was seen in a study done by Dieguez et al. ${ }^{25}$

Among women with thyroid autoimmunity, hypothyroidism may occur because of the stress of pregnancy, as the ability of the thyroid to augment hormone production is compromised. In our study, we found $6.4 \%$ of total cases hypothyroidism with positive TPO-Ab. In 1994, Glinoer et al, in his study showed asymptomatic autoimmune thyroid disorders (AITD) who are euthyroid in early pregnancy carry a significant risk of developing hypothyroidism progressively during gestation. ${ }^{26}$ Negro et al and Gayathri et al, also demonstrated similar results in their studies. ${ }^{27,28}$

Prevalence of hyperthyroid in pregnancy was $3.3 \%$, out of which Overt hyperthyroidism was $0.7 \%$ and subclinical hyperthyroidism was $2.6 \%$. This result was comparable to other studies. In the study done by Dieguez et al, they found $0.9 \%$ was of overt hyperthyroidism and $0.8 \%$ cases of subclinical hyperthyroidism. ${ }^{29}$ Hyperthyroidism was $2.0 \%, 0.8 \%$ and $0.5 \%$ in the studies of Casey et $a l$, Singh et al and Jayanthy et al respectively. ${ }^{9,22,24}$

Treatment was given to all TD pregnant females at first trimester as soon as the diagnosis was made. Only two cases had normal TSH at first trimester, hypothyroidism was detected in second trimester and treated. In our study, the prevalence of abortion, anemia, IUGR, preterm labor and $\mathrm{PPH}$ were high in hypothyroidism in compare to euthyroid pregnant but statistically not significant, which could probably be the result of an early detection and a good thyroid control with medications. Inspite of good thyroid control with medications, pregnancy related hypertention (PIH and PET) were significantly high in overt and subclinical hypothyroid pregnant. This is similar to several other studies. ${ }^{22-24,29,30}$

In a study done by Sing et al, hypothyroidism was significantly associated with preeclampsia $(\mathrm{p}=$ $0.0001)$ and IUGR $(p=0.009)$ and no significant increase in miscarriage, anemia, gestational diabetes (GDM), preterm labor, still birth and
PPH was seen, ${ }^{22}$ but in a study of Jayanthy et al it was seen that pre-eclampsea, GDM/DM, Preterm delivery, preterm/LBW and neonatal morbidity was significantly high in hypothyroidism in compared to euthyroid pregnancy. ${ }^{24}$ Other maternal and fetal complications are not significantly increased in his study.

In the review article of Nazarpour et al, it was mentioned that $\mathrm{OH}$ was associated with abortion, anemia, pregnancy-induced hypertension, preeclampsia, placental abruption, $\mathrm{PPH}$, premature birth, low birth weight, intrauterine fetal death, increased neonatal respiratory distress and infant neuro developmental dysfunction. However the adverse effect of $\mathrm{SCH}$, and thyroid antibody positivity on pregnancy outcomes was not clear. ${ }^{29}$ Manjunatha et al in his study showed significant increase in the TSH levels in pre-eclampsia than in normal pregnancy and proved thyroid disorder as one of the predisposing causes for pre-eclampsia. ${ }^{30}$ Rate of LSCS was also significantly high in hypothyroid than in euthyroid pregnancy and cause was mostly due to fetal distress. ${ }^{22,23}$

Very high prevalence of hypothyroidism in pregnancy and its severe complication like gestational hypertension and pre-eclapsea, even after treatment in this study shows necessity of universal screening of TD and its management. Early antenatal visit and universal screening of TD in first trimester is important. Most of the complication can be avoided if treated on time. Studies from Nepal shows very high prevalence of hypothyroidism. ${ }^{18,19}$ By treating hypothyroidism in early pregnancy, we can reduce the fetal and maternal mortality and come up with excellent fetal maternal outcome.

\section{ACKNOWLEDGEMENT}

My special thanks to the residents of Obstetrics and Gynaecology Department who helped me in collecting the data.

\section{REFERENCES}

1. Abalovich M, Amino N, Barbour L et al. Management of thyroid dysfunction during pregnancy and postpartum: An endocrine society clinical practice guideline. J Clin Endocrinol Metab 2007; 97: 1-47.

2. Grossman M, Weintrau BD, Szkudlinski MW. Novel Insights into the molecular mechanisms of human thyrotropin action: structural physiological and therapeutic implications further glycoprotein hormone family. Endocr Rev 1997; 18: 476-501.

3. Vulsma T, Gons MH, Vijlder JJ. Maternal-fetal transfer of thyroxine in congenital hypothyroidism 
due to a total organification defect or thyroid agenesis. N Engl J Med 1989; 321: 13-6.

4. Bernal J. Thyroid hormone receptors in brain development and function. Nat Clin Pract Endocrinol Metab 2007; 3: 249-59.

5. Wang W, Teng W, Shan Z et al. The prevalence of thyroid disorders during early pregnancy in China: The benefits of universal screening in the first trimester of pregnancy. Eur J Endocrinol 2011; 164: 263-8.

6. Clearly-Goldman J, Malone FD, Lambert-Messerlian $\mathrm{G}$ et al. Maternal thyroid hypofunction and pregnancy outcome. Obstet/Gynecol 2008; 112: 8592.

7. Vaidya B, Anthony S, Bilous M et al. Detection of thyroid dysfunction in early pregnancy: Universal screening or targeted high-risk case findings? J Clin Indocrinol Metab 2007; 92: 203-7.

8. Casey BM, Dashe JS, Wells CE et al. Subclinical hypothyroidism pregnancy outcomes. Obstet/ Gynecol 2005; 105: 239-45.

9. Casey BM and Leveno KJ. Thyroid disease in pregnancy. Obstet/Gynecol 2006; 108: 1283-92.

10. Davis LE, Leveno KJ, and Cunningham FG. Hypothyroidism complicating pregnancy. Obstetrics/Gynecology 1988; 72: 108-12.

11. Leung AS, Millar LK, Koonings PP, Montoro M, and Mestman JH. Perinatal outcome in hypothyroid pregnancies. Obstetrics/Gynecology 1993; 81: 34953.

12. Allan WC, Haddow JE, Palomaki GE et al. Maternal thyroid deficiency and pregnancy complications: implications for population screening. J Med Screen 2000; 7: 127-30.

13. Abalovich M, Gutierrez S, Alcaraz G, Maccallini G, Garcia A, Levalle O. Overt and subclinical hypothyroidism complicating pregnancy. Thyroid 2002; 12: 63-8.

14. Casey BM, Dashe JS, Wells CE et al. Subclinical hypothyroidism and pregnancy outcomes. Obstet/ Gynecol 2005; 105: 239-45.

15. Haddow JE, Palomaki GE, Allan WC et al. Maternal thyroid deficiency during pregnancy and subsequent neuropsychological development of the child. N Engl J Med 1999; 341: 549-55.

16. Stricker R, Echenard M, Eberhart R et al. Evaluation of maternal thyroid function during pregnancy: the importance of using gestational age-specific reference intervals. European J Endocrinol 2007; 157: 509-14.

17. Lazarus JH. Thyroid functions in pregnancy. $\mathrm{Br}$ Med Bull 2011; 97: 137-48.
18. Upadhyaya TL, KC A, Paudel S. Prevalence and complications of Hypothyroidism during pregnancy in western Nepal. Nepal J Med Sci 2014; 3: 48-50.

19. Chaudhary LN, Khatiwada S, Gelal B et al. Iodine and Thyroid Function Status, and Anti-thyroid Peroxidase Antibody among Pregnant Women in Eastern Nepal. J Nepal Health Res Counc 2017; 15: 114-9.

20. World Bank, Nutrition in Nepal: A National Development Priority, World Bank, Washington, DC, USA, 2012, http://documents.worldbank.org/ curated/en/2012/01/16259424/nutrition-nepalnational-development-priority.

21. Siva N. Sprinkle of salt needed for Nepal's hidden hunger. World Report 2010; 376: 673-4.

22. Singh A, Reddy MJ. Prevalence of thyroid dysfunction in pregnancy and its implications. Int'l J Med Sci Public Health 2015; 4: 1247-50.

23. Sahu MT, Das V, Mittal S, Agarwal A, Sahu M. Overt and subclinical thyroid dysfunction among Indian pregnant women and its effect on maternal and fetal outcome. Arch Gynecol Obstet 2010; 281: 21520.

24. Jayanthy T. Screening for thyroid disorders in pregnancy with TSH estimation. Int'l J Reprod Contracept Obstet Gynecol 2016; 5: 1052-5.

25. Dieguez M, Herrero A, Avello N, Suarez P, Delgado E and Menendez E. Prevalence of thyroid dysfunction in women in early pregnancy: does it increase with maternal age? Clin Endocrinol 2016; 84: 121-6.

26. Glinoer D, Riahi M, Grün JP, Kinthaert J. Risk of subclinical hypothyroidism in pregnant women with asymptomatic autoimmune thyroid disorders. J Clin Endocrinol Metabol 1994; 79: 197-204.

27. Negro R, Formoso G, Mangieri T, Pezzarossa A, Dazzi D, Hassan H. Levothyroxine treatment in euthyroid pregnant women with autoimmune thyroid disease: effects on obstetrical complications. J Clin Endocrinol Metabol 2006; 91: 2587-91.

28. Gayathri R, Lavanya S, Raghavan K. Subclinical hypothyroidism and autoimmune thyroiditis in pregnancy-A study in south Indian subjects. $J$ Assoc Physicians India 2009; 57: 691-3.

29. Nazarpour S, Tehrani FR, Simbar M, Azizi F. Thyroid dysfunction and pregnancy outcomes. Int'l J Reprod Bio Med 2015; 13: 387-96.

30. Manjunatha S, Basavraja GN, Patil RS. Thyroid Dysfunction in Pregnancy and Preeclampsia. Sch J App Med Sci 2014; 2: 3297-9. 